\title{
Thick calcification from a GIST of the stomach penetrating into pericolic soft tissue - report of a case
}

\author{
Cheng-Chan $\mathrm{Yu}^{1 *}$, Cheng-Chung Wu', Jen-l Hwang ${ }^{2}$, John Wang ${ }^{3}$ and Chi-Sen Chang ${ }^{4}$
}

\begin{abstract}
Thick calcification is a rare presentation of gastrointestinal stromal tumor (GIST). Penetration into gastric mucosa and pericolic soft tissue has never been reported. We report a case of gastric GIST with cystic degeneration and thick calcification in an 81-year old female, who presented with hematemesis and severe abdominal pain. Thick calcification of this tumor penetrating into pericolic soft tissue was noted and successfully treated by distal gastrectomy and partial colectomy. For gastrointestinal tumors with thick calcification, even with benign behavior, surgical intervention should be considered for both oncological considerations and prevention of catastrophes like perforation or penetration into surrounding soft tissue.
\end{abstract}

\section{Introduction}

Calcification within primary gastrointestinal stromal tumor(GIST) has been reported [1-3], but thick calcification within GIST is rare [1]. Thick calcification of a GIST penetrating into surrounding soft tissue has never been reported. Herein, we report the first case of thick calcification from a gastric GIST with cystic degeneration penetrating into pericolic soft tissue.

\section{Case presentation}

An 81-year-old female with hypertension and gout was admitted to Taichung Veterans General Hospital due to abdominal pain and hematemesis. She began to suffer from intermittent epigastralgia more than 10 years ago, and a $4 \mathrm{~cm}$ gastric tumor was found. The abdominal pain got worse 2 years before admission, and she went to a local hospital where abdominal CT scan revealed a gastric tumor about $6 \mathrm{~cm}$ in length with well-circumscribed calcification(figure 1). Surgical intervention was suggested, but she declined. About 10 days before admission, tarry stool passage was noted, and bloody vomitus was found 1 day later. UGI scope revealed submucosal gastric tumor with central ulceration and she was then transferred to our hospital.

\footnotetext{
* Correspondence: jefferyu@gmail.com

'Department of Surgery, Taichung Veterans General Hospital, No. 160, Sec. 3, Taichung-Kang Rd., Taichung, 40705, Taiwan

Full list of author information is available at the end of the article
}

Physical examination showed upper abdominal tenderness with mild muscle guarding. The plain radiography showed an irregular shape calcification over upper abdomen. UGI scope revealed deep gastric ulcer with foreign body. CT scan showed an irregularly shaped space-occupying lesion in front of the stomach with plate calcifications and localized free air (figures 2 and 3 ). Under the impression of perforated gastric tumor, emergent laparotomy was performed. An infiltrative mass between the stomach and transverse colon was noted during operation. A sharp, bone-like and thick calcified plate penetrating into the gastric mucosa and pericolic soft tissue was observed. A submucosal tumor about $2.3 \mathrm{~cm}$ in size adherent to the calcified plate was also noted (figures 4 and 5). Distal subtotal gastrectomy and partial colectomy were performed. The patient was discharged 13 days after operation uneventfully. Microscopically, spindle-shaped tumor cells with low mitotic frequency (4/50 HPF) were found. Immunohistochemical staining of the tumor demonstrated diffusely strong positive reactivity for $\mathrm{CD} 117$, positive reactivity for CD34, but negative reactivity for $\mathrm{S} 100$ protein and desmin. The diagnosis of the tumor was established as GIST. Due to the small size and the paucity of mitotic figures of the tumor located in the stomach, it was classified as very low risk [4]. Sporadic GIST was impressed due to no family history of GIST nor other GIST presented in this patient. 


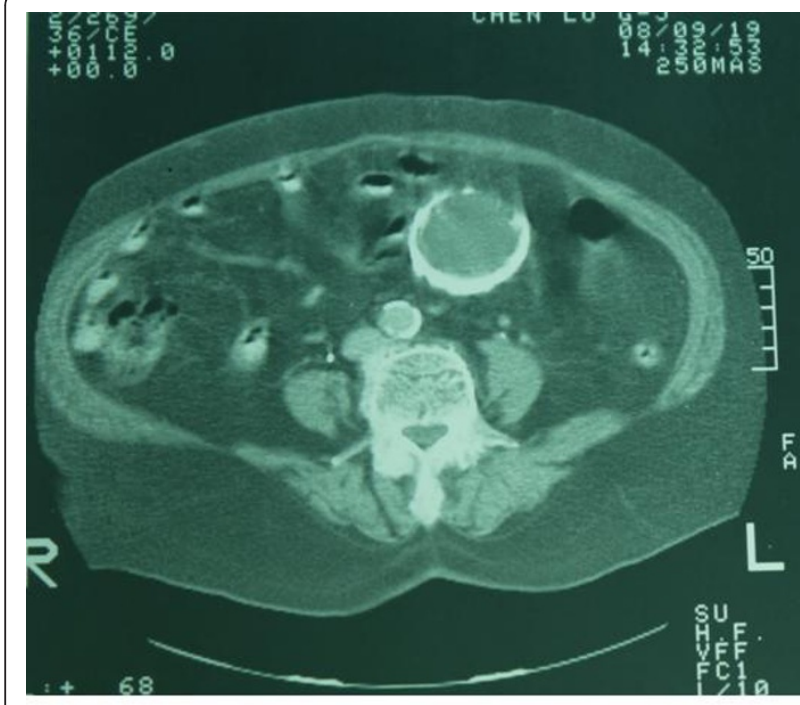

Figure 1 Gastric mass with circumscribed calcification was found by the CT scan 2 years ago. Greater thickness over the dependent part was noted.

\section{Discussion}

GISTs are uncommon tumors originating from the interstitial cells of Cajal, which are pacemaker cells regulating autonomic motor activity in the gastrointestinal tract. The majority of the GISTs arise in the stomach (60-70\%), followed by small intestine, colon, esophagus, omentum, and mesentery $[2,3]$. The tumor size, mitotic figures and the organ of origin determine the biological behavior of GIST [4]. Patients with GIST may present with abdominal pain, satiety, obstruction, or GI bleeding. However,

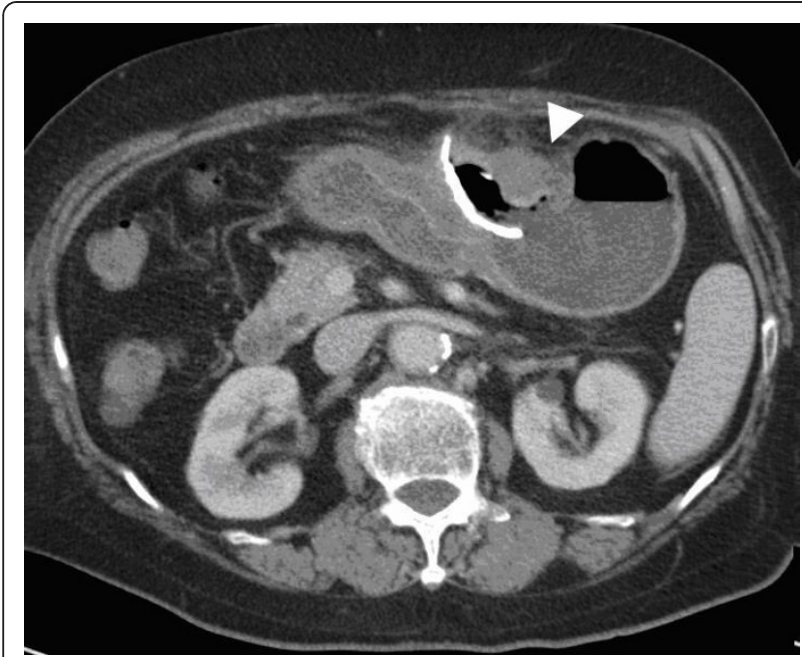

Figure 2 Pre-operative CT scan showed gastric mass with curvilinear calcification penetrating into surrounding soft tissue. Localized abscess formation was noted. A gastric tumor adjacent to the calcification was noted.

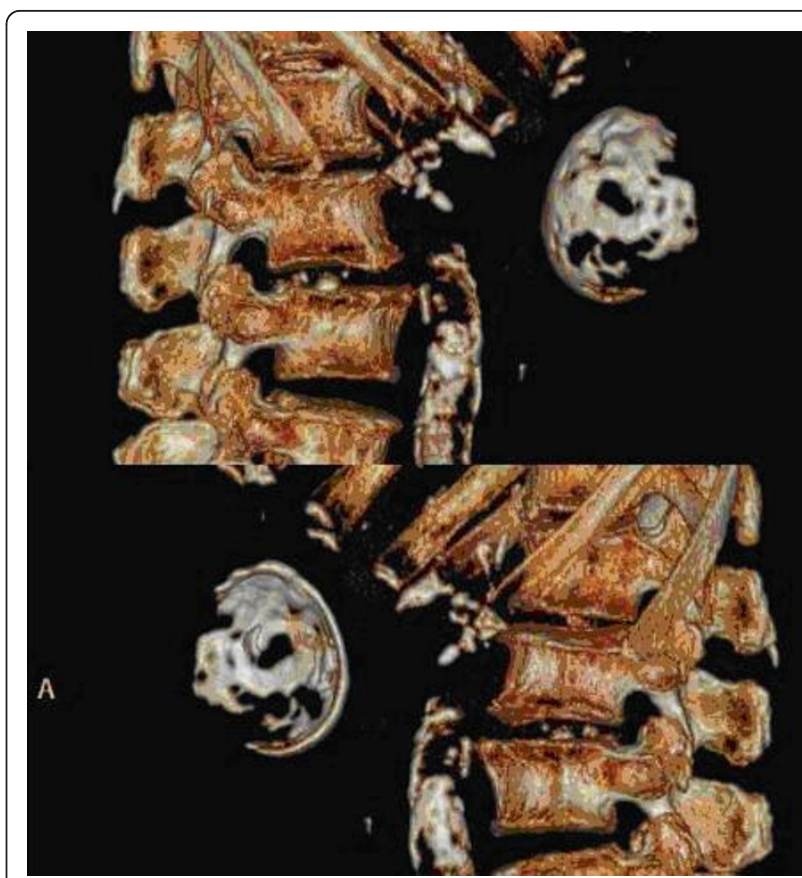

Figure $33 \mathrm{DCT}$ reconstruction showed an unusual semicircular calcified plate in the upper abdomen. (upper: Right side view, lower Left side view) Ingested foreign body was excluded by history and large size of the calcification.

thick calcification of a GIST penetrating into pericolic soft tissue has never been reported.

CT is considered to be the imaging modality of choice for the detection, staging, surgical planning, and followup of patients with GIST [5,6]. Most tumors are seen as well delineated soft tissue masses with heterogenous contrast enhancement. Necrosis, calcification, and ulceration are most commonly seen in large tumors that present a more aggressive behavior [6].

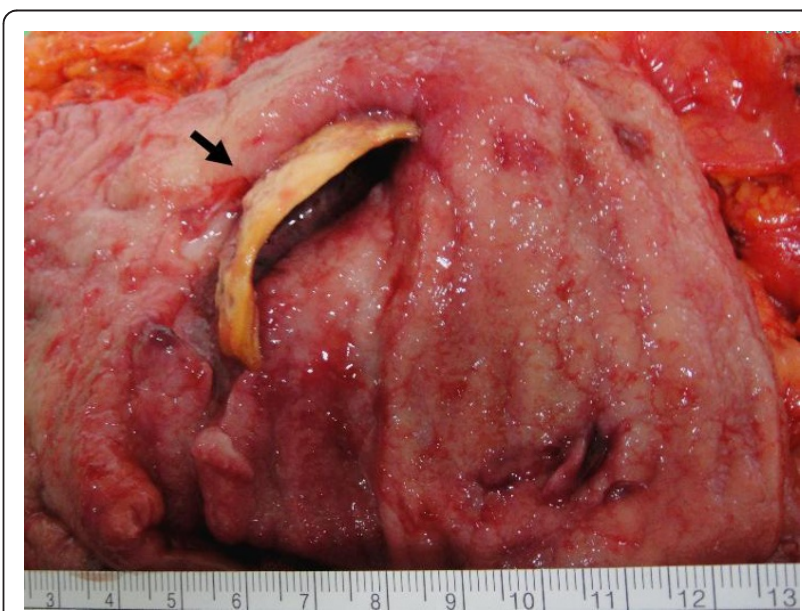

Figure 4 Thick calcification with deep ulceration (black arrow) penetrating into pericolic soft tissue with abscess formation was noted. 


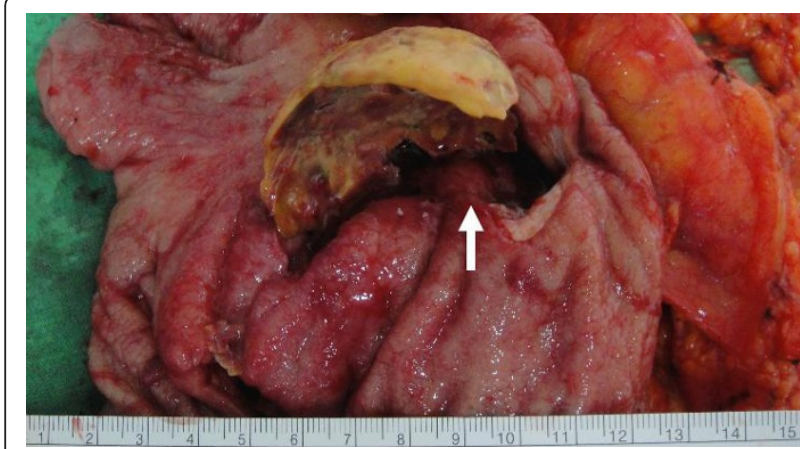

Figure 5 Gastric tumor(white arrow) adherent to the calcified plate was also noted.

Focal calcification within GIST has been reported, ranging from $10 \%$ to $50 \%$ in reported series [6-8]. However, extensive thick calcification visible on plain radiograph is a rare phenomenon $[1,8]$. Most calcifications within GIST are circumscribed and patchy type. Previous episodes of bleeding or tumor necrosis with cystic degeneration may cause calcification [9-11]. In our case, the CT scan 2 years ago showed a cystic tumor with well circumscribed calcification in the stomach, but with greater thickness over the dependent part. The preoperative CT scan with 3D reconstruction showed gastric mass with curvilinear calcification, which was identical to the operative finding. Less aggressive tumor behavior (very low risk by pathological classification) and long history of tumor presenting in this patient (more than 10 years) contributed to the development the thick calcification. The cause of the penetration was thought to be the sharp edge of the ruptured calcified cystic wall penetrating into the gastric lumen and pericolic soft tissue.

Other gastrointestinal tumors may also contain calcification. At least three types of calcification have been reported in gastric cancer: mucin pool calcifications, psammomatous calcifications, and heterotopic ossification $[9,12]$. In addition, four mechanisms of calcification within tumor have been suggested: (a) calcified scar tissue or granulomatous disease is engulfed by the tumor; (b) dystrophic calcification occurs within the areas of tumor necrosis; (c) calcium is deposited within the tumor as a result of a secretory function of the carcinoma; (d) metastatic calcification occurs as a result of hypercalcemia [13,14]. Mucin-forming tissues are prone to develop calcification due to the presence of mucinous material and a relatively alkaline environment, which is helpful for precipitation of calcium ions. The presence of diffuse, punctate calcifications in gastric mass is thought to be diagnostic for mucinous adenocarcinoma. Dystrophic calcification occurs in ischemic and necrotic tissue. Denatured proteins bind specifically to phosphate ions and thereafter react with calcium ions to form calcium phosphate precipitates. The relatively alkaline environment readily facilitates precipitation.

An ingested foreign body in the stomach may mimic gastric calcification. Ingested animal bone was considered initially in our case, but was excluded later due to the huge size of the calcification and because a comparison of the CT scan with an image obtained two years earlier showed that this was unlikely.

In conclusion, herein we report the first case of thick calcification from a gastric GIST with cystic degeneration penetrating into pericolic soft tissue which was successfully treated by partial gastrectomy and colectomy. For gastrointestinal tumors with thick calcification, even with benign behavior, surgical intervention should be considered for both oncological considerations and prevention of catastrophes like perforation or penetration into surrounding soft tissue.

\section{Consent}

Written informed consent was obtained from the patient for publication of this case report and any accompanying images. A copy of the written consent is available for review by the Editor-in-Chief of this journal.

List of abbreviations

GIST: gastrointestinal stromal tumor

\section{Acknowledgements and Funding}

The authors thank Department of medical research of Taichung Veterans General Hospital for providing English correction. Written consent for publication was obtained from the patient or their relative.

\section{Author details}

${ }^{1}$ Department of Surgery, Taichung Veterans General Hospital, No. 160, Sec. 3, Taichung-Kang Rd., Taichung, 40705, Taiwan. Department of Radiology, Taichung Veterans General Hospital, No. 160, Sec. 3, Taichung-Kang Rd., Taichung, 40705, Taiwan. ${ }^{3}$ Department of Pathology, Taichung Veterans General Hospital, No. 160, Sec. 3, Taichung-Kang Rd., Taichung, 40705, Taiwan. ${ }^{4}$ Department of Medicine, Taichung Veterans General Hospital, No. 160, Sec. 3, Taichung-Kang Rd., Taichung, 40705, Taiwan.

\section{Authors' contributions}

All authors conceived of the study, and participated in its design and coordination and helped to draft the manuscript. All authors read and approved the final manuscript.

\section{Competing interests}

The authors declare that they have no competing interests.

Received: 1 January 2011 Accepted: 29 April 2011 Published: 29 April 2011

\section{References}

1. Ong K, Singaporewalla RM, Tan KB: Extensive calcification within a gastrointestinal stromal tumour: a potential diagnostic pitfall. Pathology 2006, 38(5):451-452.

2. Liegl-Atzwanger B, Fletcher JA, Fletcher CD: Gastrointestinal stromal tumors. Virchows Arch 2010, 456(2):111-127.

3. Miettinen M, Lasota J: Gastrointestinal stromal tumors-definition, clinical, histological, immunohistochemical, and molecular genetic features and differential diagnosis. Virchows Arch 2001, 438(1):1-12. 
4. Miettinen M, Lasota J: Gastrointestinal stromal tumors: pathology and prognosis at different sites. Semin Diagn Pathol 2006, 23(2):70-83.

5. Chourmouzi D, Sinakos E, Papalavrentios L, Akriviadis E, Drevelegas A: Gastrointestinal stromal tumors: a pictorial review. J Gastrointestin Liver Dis 2009, 18(3):379-383.

6. Darnell A, Dalmau E, Pericay C, Musulen E, Martin J, Puig J, Malet A, Saigi E, Rey M: Gastrointestinal stromal tumors. Abdom Imaging 2006, 31(4):387-399.

7. Chamadol N, Laopaiboon V, Promsorn J, Bhudhisawasd V, Pagkhem A Pairojkul C: Gastrointestinal stromal tumor: computed tomographic features. J Med Assoc Thai 2009, 92(9):1213-1219.

8. Levy AD, Remotti HE, Thompson WM, Sobin LH, Miettinen M: Gastrointestinal stromal tumors: radiologic features with pathologic correlation. Radiographics 2003, 23(2):283-304, 456; quiz 532.

9. Dickson AM, Schuss A, Goyal A, Katz DS: Radiology-Pathology Conference: Calcified untreated gastric cancer. Clin Imaging 2004, 28(6):418-421.

10. Testroote M, Hoornweg M, Rhemrev S: Rectal GIST presenting as a submucosal calculus. Dig Dis Sci 2007, 52(4):1047-1049.

11. Yoshida H, Mamada Y, Taniai N, Mizuguchi Y, Nakamura Y, Nomura T, Okuda T, Uchida E, Fukuda Y, Watanabe M, et al: Spurt bleeding from a calcificated gastrointestinal stromal tumor in the stomach. J Nippon Med Sch 2005, 72(5):304-307.

12. Balestreri $\mathrm{L}$, Canzonieri V, Morassut S: Calcified gastric cancer-CT findings before and after chemotherapy. Case report and discussion of the pathogenesis of this type of calcification. Clin Imaging 1997, 21(2):122-125

13. Yasushi Itoua TRKaST: A case of intraductal tubular adenocarcinoma of the pancreas that developed extensive intratumoral calcification. European Journal of Radiology Extra 2009, 71(2):e65-e69.

14. Aydemir S, Savranlar A, Engin H, Cihan A, Ustundag Y, Ozer T, Dogan Gun B: Gastric wall calcification in gastric cancer relapse: case report. Turk J Gastroenterol 2006, 17(1):50-52

doi:10.1186/1477-7819-9-45

Cite this article as: Yu et al:: Thick calcification from a GIST of the stomach penetrating into pericolic soft tissue - report of a case. World Journal of Surgical Oncology 2011 9:45.

\section{Submit your next manuscript to BioMed Central} and take full advantage of:

- Convenient online submission

- Thorough peer review

- No space constraints or color figure charges

- Immediate publication on acceptance

- Inclusion in PubMed, CAS, Scopus and Google Scholar

- Research which is freely available for redistribution

Submit your manuscript at www.biomedcentral.com/submit
Biomed Central 